\title{
THE EFFECT OF DIFFERENT DOSE OF DROP JUMPING ON SYMPTOMS OF MUSCLE DAMAGE
}

\author{
Albertas Skurvydas, Gediminas Mamkus, Dalia Mickevičienė, Diana Karanauskienė, \\ Dovilė Valančienė, Mantas Mickevičius, Sigitas Kamandulis \\ Lithuanian Sports University, Kaunas, Lithuania
}

\begin{abstract}
Background. The aim of this study was to follow symptoms of exercise induced muscle damage in response to 50, 100 and 200 drop jumps with maximal intensity.

Methods. Three groups of young healthy men ( $n=10$ in each group) performed a bout of mechanically demanding stretch shortening cycle exercise consisting of 50,100 and 200 drop jumps. Voluntary and electrically induced knee extension torque, creatine kinase, muscle soreness were measured before and $24 \mathrm{~h}$ after exercise.

Results. Indirect symptoms of exercise induced damage were dependent on DJs volume: the higher the numbers of jumps, the more symptoms were observed. Only after 200 DJs compared to 50-100 DJ there was decrease of CAR and $\mathrm{H}$ of DJ, and $24 \mathrm{~h}$ after 200 DJs CK was greater than after 50-100 DJs.

Conclusion. In response to acute severe muscle-damaging exercise (after 200 DJs), indirect symptoms of exercise-induced muscle damage occurred.
\end{abstract}

Keywords: stretch-shortening cycle exercise, motor fatigue, muscle soreness, muscle torque.

\section{INTRODUCTION}

$\mathrm{R}$ esistance and jumping exercises involving stretch-shortening muscular contractions may induce muscle damage (Byrne, Twist, \& Eston, 2004; Gorianovas et al. 2013; Skurvydas, Brazaitis, Venckūnas, \& Kamandulis, 2011) and result in a prolonged depression in muscle force, especially that is induced by low-frequency stimulation (Allen, Lamb, \& Westerblad, 2008; Kamandulis, Skurvydas, Masiulis, Mamkus, \& Westerblad, 2010; Proske \& Allen, 2005; Skurvydas \& Zachovajevas, 1998), and voluntary muscle activation (Fouré et al. 2014). In addition, increased plasma activity of muscle enzymes such as creatine kinase (CK) (Choi, 2014) is often observed. It is generally agreed that muscle tension and muscle length are main factors in determining the magnitude of exercise-induced muscle damage (EIMD (Proske \& Allen, 2005). Basically it was concluded that the number of contractions performed could not explain the variability in EIMD markers among studies. However, a large fraction of muscle damage may occur early during exercise with further increase in the number of eccentric contractions causing progressively less damage (Morgan \& Allen, 1999). Though the decrease in isometric and concentric torque and muscle soreness was smaller after 10 DJs compared with 50 DJs (Miyama \& Nosaka, 2007), it has been shown that increase in the number further than 50 drop jumps did not increase electrically stimulated force reduction (Kamandulis et al., 2010). These facts suggest that severity of muscle damage might have very different effect on muscle damage markers.

Therefore, the aim of the present study was to compare the indirect symptoms of exercise induced muscle damage after 50, 100 and 200 drop jumps. 


\section{METHODS}

Subjects. Three groups including 10 healthy untrained men participated in the study. The subjects' age, height and weight were similar (1924 years, height $=179.9 \pm 3.6 \mathrm{~cm}$, body weight $=$ $77.2 \pm 4.5 \mathrm{~kg}$ ). Subjects had not been involved in any type of systematic resistance or plyometric training program for at least 6 months before the study. Before being included into the study, subjects read and voluntarily signed an informed consent form consistent with the principles outlined in the Declaration of Helsinki. The study was approved by the Regional Ethics Committee.

Stretch-shortening cycle exercise. Subjects performed 50 (group of 50 DJs), 100 (group of 100 DJs) and 200 (group of 200 DJs) intermittent (30 s interval between each) drop jumps (DJs) from a $0.5 \mathrm{~m}$ height to a $90^{\circ}$ knee angle with immediate maximal vertical rebound. Knee angle was controlled and recorded using a goniometer (Biometrics, UK). If the angle diverged from $90^{\circ}$ during exercise, subjects were immediately instructed to adjust it on the subsequent jumps. During jumping, subjects held their hands on their waists. Jumps were performed using a contact mat (Power Timer Testing System, Newest, Finland). The rebound jump height (in $\mathrm{cm}$ ) was calculated as (flight time in seconds) ${ }^{2} \times 122.6$ (BOSCO, Viitasalo, Komi, \& Luhtanen, 1982). The highest jump values of the first and last three of 50, 100, 200 DJs and at $24 \mathrm{~h}$ post-exercise were used in the analyses.

Knee extension torques. Torque of knee extensor muscles on the dominant leg was measured using an isokinetic dynamometer (System 3; Biodex Medical Systems, Shiley, New York). Subjects seated themselves upright in the dynamometer chair with their knee joint positioned at $110^{\circ}$ angle (where $180^{\circ}$ is full knee extension). Maximal voluntary knee extension for $\sim 2 \mathrm{~s}$ was attempted twice; the larger value was used in analyses. The equipment and procedure for electrical stimulation were the same as in our previous studies (Skurvydas et al., 2011; Verbickas et al., 2018). Direct muscle stimulation was applied using two carbonized rubber surface electrodes, covered with a thin layer of electrode gel (Medigel, Modi'in, Israel). One electrode $(6 \times 11 \mathrm{~cm})$ was positioned on the skin transversely across the width of the proximal portion of the quadriceps femoris. Another electrode $(6 \times 20$ $\mathrm{cm})$ covered the distal portion of the muscle above the patella. A standard electrical stimulator (MG 440; Medicor, Budapest, Hungary) was used to deliver supramaximal $0.5 \mathrm{~ms}$ square-wave pulses at 20 and $100 \mathrm{~Hz}$ frequencies for P20 and P100 torque measurement, respectively. Low-frequency fatigue (reflected as a drop in P20/P100 ratio) was calculated. The central activation was measured during $\sim 5 \mathrm{~s}$ of maximal voluntary contraction; at $\sim 3 \mathrm{~s}$ after beginning the attempt, a $250 \mathrm{~ms}$ test train of pulses at $100 \mathrm{~Hz}$ (TT100) was superimposed while the subject continued maximal efforts of knee extension. The central activation was calculated as the ratio of the maximal voluntary torque to peak torque generated with a superimposed TT100 (Gorianovas et al., 2013). The test was performed twice, and the larger central activation ratio value was used in the analyses.

Plasma creatine kinase (CK) activity. Approximately $0.5 \mathrm{~mL}$ of mixed capillary blood was drawn from the subject's fingertip at baseline and $24 \mathrm{~h}$ post-exercise. Samples were immediately centrifuged and the plasma analysed for creatine kinase activity using the biochemical analyzer Spotchem $^{\mathrm{TM}}$ EZ SP-4430 (Menarini Diagnostics, UK) with soft reagent strips (ARKRAY Factory, Inc., Shiga, Japan).

Muscle soreness. Muscle soreness was reported subjectively using an ordinal scale of $0-10$, where 0 represented "no pain" and 10 represented "intolerably intense pain" (Kamandulis et al., 2010). Subjects rated the severity of soreness in their quadriceps while performing 2-3 slow squats at baseline, and then on day $1(24 \mathrm{~h})$ post-exercise.

Statistical Analysis. Descriptive data are presented as means and standard deviation (SD). A Kolmogorov-Smirnov test confirmed that all data were normally distributed. One-way repeatedmeasures analysis of variance (ANOVA) was used to identify differences. Statistical significance was set at $p<.05$. Data analysis was performed using SPSS 22.0 statistical software package (SPSS Inc. Chicago, IL).

\section{RESULTS}

Motor performance. There was no significant difference between the values of motor performance pre-exercise in the groups (Table). MVC after exercise decreased for all groups $(p<.001 ; O P=1)$, but after 200 DJs it decreased more than after 100 DJs and 50 DJs $(p<.01)$ (Figure 1A). Besides, $24 \mathrm{~h}$ after 200 DJs and 100 DJs MVC did not recover. CAR significantly decreased only after 200 DJs 
Table 1. Pre-exercise values of muscle torque and power indices (mean \pm SD)

\begin{tabular}{|c|c|c|c|c|c|}
\hline Group & $\operatorname{MVC}(\mathbf{N} \cdot \mathbf{m})$ & DJs height (cm) & $\begin{array}{c}\text { P20 } \\
(\mathbf{N} \cdot \mathbf{m})\end{array}$ & $\begin{array}{l}\mathrm{P} 100 \\
(\mathbf{N} \cdot \mathbf{m})\end{array}$ & $\begin{array}{c}\text { CAR } \\
(\%)\end{array}$ \\
\hline $50 \mathrm{DJs}$ & $\begin{array}{c}291.6 \\
71.5\end{array}$ & $\begin{array}{c}36.8 \\
6.8\end{array}$ & $\begin{array}{c}166.5 \\
29.9\end{array}$ & $\begin{array}{c}245.2 \\
45.6\end{array}$ & $\begin{array}{c}95.8 \\
7.5\end{array}$ \\
\hline $100 \mathrm{DJ}$ & $\begin{array}{c}290.9 \\
44.3\end{array}$ & $\begin{array}{c}35.1 \\
4.5\end{array}$ & $\begin{array}{c}178.1 \\
24.4\end{array}$ & $\begin{array}{c}254.2 \\
38.1\end{array}$ & $\begin{array}{c}95.4 \\
8.0\end{array}$ \\
\hline $200 \mathrm{DJs}_{\mathrm{s}}$ & $\begin{array}{c}279.1 \\
40.3\end{array}$ & $\begin{array}{c}34.9 \\
5.9\end{array}$ & $\begin{array}{c}169.1 \\
29.9\end{array}$ & $\begin{array}{c}259.9 \\
31.1\end{array}$ & $\begin{array}{c}94.4 \\
7.3\end{array}$ \\
\hline
\end{tabular}

Note. MVC - maximal voluntary contraction torque; P20 and P100 - electrical stimulation at 20 and $100 \mathrm{~Hz}$ evoked torque; CAR - central activation ratio; DJs - drop jumps.

and did not recover within $24 \mathrm{~h}(p<.01)$ (Figure 1B). H of DJs significantly decreased only after 100 and 200 DJ $(p<.01)$, but after 200 DJs it decreased more than after 100 DJs $(p<.05)$ (Figure 2).

$\mathrm{P} 20, \mathrm{P} 100$ and P20/P100 decreased significantly after 50, 100 and 200 DJs and it did not recover within $24 \mathrm{~h}(p<.001 ; O P=1)$ (Figure 3$)$. However,
P20, P100 and P20/P100 decreased more after 100 and P200 DJs than after 50 DJs $(p<.01)$.

Muscle soreness and CK were greater after 100 and 200 DJs than after 50 DJs $(p<.01)$ (Figure 4A and $4 \mathrm{~B}$ ). There was no difference in muscle soreness after 100 DJs and 200 DJs, however, CK after 200 DJs was greater than after 100 DJs $(p<.01)$.

Figure 1. MVC (A) and CAR (B) changes after 50, 100 and 200 DJs

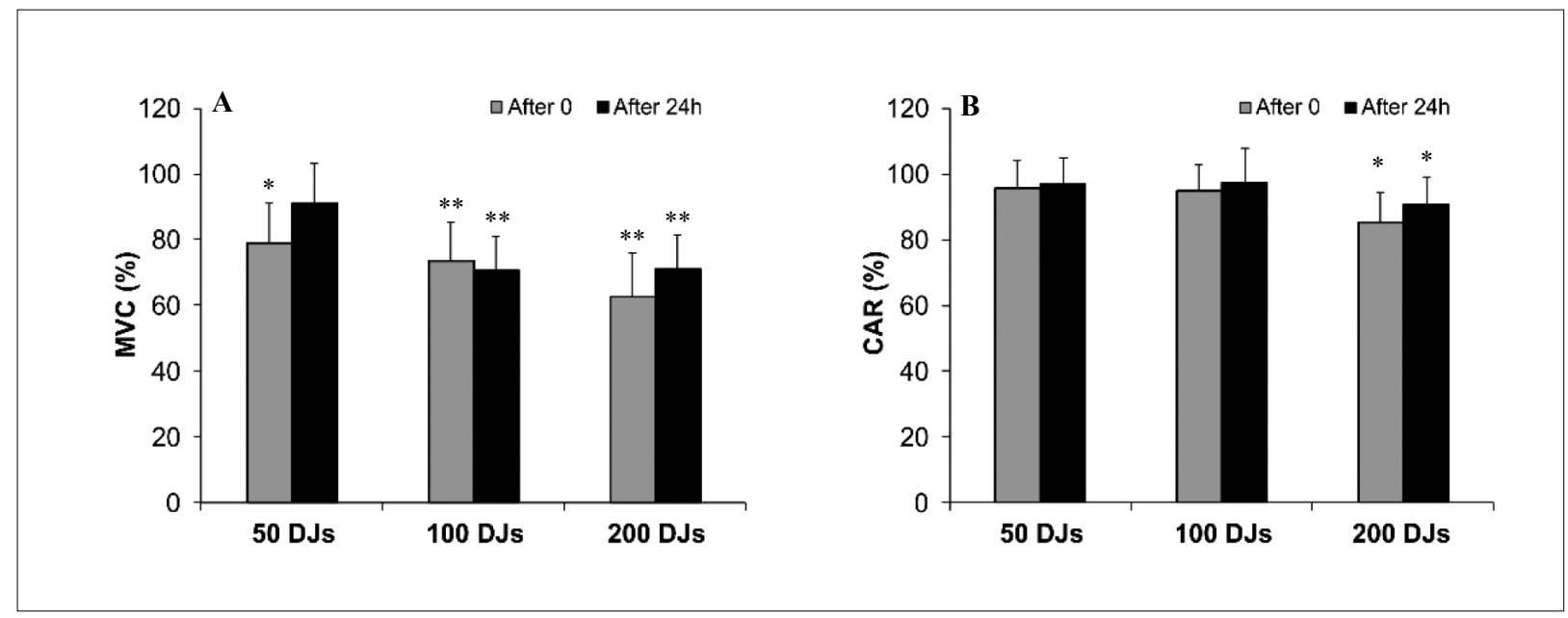

Note. $* p<.05$ and $* * p<.001$ compared to pre-exercise values.

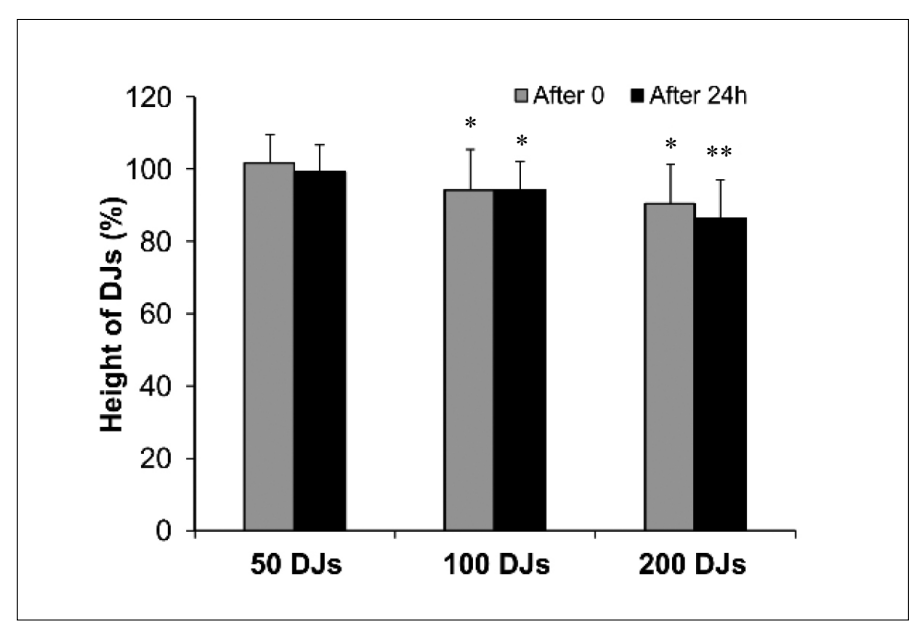

Figure 2. Height of drop jumps (DJs) changes after 50, 100 and 200 DJs

Note. ${ }^{*} p<.05$ and $* * p<.001$ compared to pre-exercise values. 
Figure 3. P20 (A), P100 (B) and P20/P100 (C) changes after 50, 100 and 200 DJs

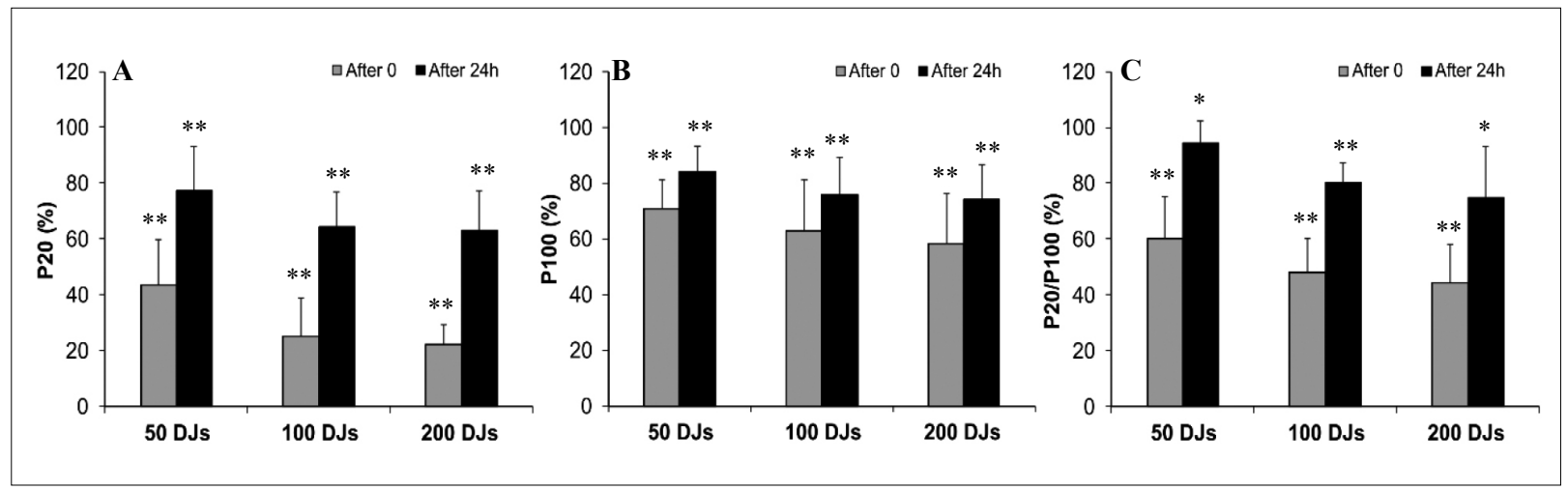

Note. $* p<.05$ and $* * p<.001$ compared to pre-exercise values.

Figure 4. DOMS (A), CK (B) changes after 50, 100 and 200 DJs
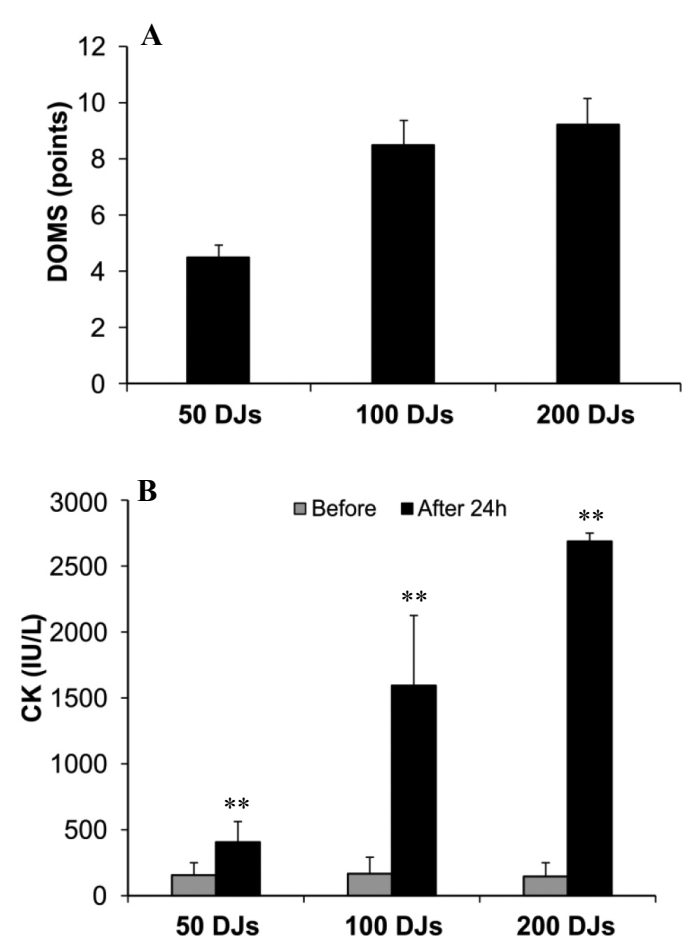

Note. $* p<.05$ and $* * p<.001$ compared to pre-exercise values.

\section{DISCUSSION}

Indirect symptoms of EIMD after 50 DJs are smaller than after 100 and 200 DJS. Compared to 100 DJS, 200 DJs increased CK and decreased voluntary motor performance. LFF remained the same after 100 and 200 DJS.

After all three exercise bouts, the symptoms of muscle damage manifested themselves: decrease in muscle voluntary and electrically induced torque, the rise of muscle soreness and increased plasma CK activity. Most symptoms show that exercise-induced muscle damage increased with the increase in DHS volume: 50 vs 100 vs 200 DS. In addition, P20 had decreased to a greater extent than the P100 suggesting that the muscles were subjected to LFF. These markers indicate that the main causes for the decrease in voluntary and electrically induced muscle performance after drop jumping are related to damage force-bearing structures (Byrne et al., 2004; Morgan \& Proske, 2004; Proske \& Allen, 2005) and excitationcontraction coupling system (Allen et al., 2008; Kamandulis et al., 2010; Verbickas et al., 2018).

The largest decrease, compared to other strength indicators, was registered for torque evoked by $20 \mathrm{~Hz}$ stimulation frequencies after 50-200 DJs. The decreased torque production of exercise-exposed muscle cells can, in principle, be due to (i) reduced $\mathrm{Ca}^{2+}$ release from the sarcoplasmic reticulum leading to decreased free myoplasmic $\left[\mathrm{Ca}^{2+}\right]\left(\left[\mathrm{Ca}^{2+}\right] \mathrm{i}\right)$, (ii) decreased myofibrillar $\mathrm{Ca}^{2+}$ sensitivity, and (iii) reduced ability of contractile machinery to produce force (Allen et al. 2008). On a simplified model, factors (i) and (ii) would result in a larger force depression rather at low than at high stimulation frequencies due to the sigmoidal shape of the force-[ $\left.\mathrm{Ca}^{2+}\right]$ i relationship, whereas factor (iii) would give a similar force decrease at all stimulation frequencies. We observed markedly larger force reductions during after SSE at 20 $\mathrm{Hz}$ than at $100 \mathrm{~Hz}$ stimulation, which indicate important roles of factor (i) and (ii) in the SSEinduced force depression (especially after 100-200 DJs). It should be noted, however, that sarcomere instability induced by eccentric contractions can shift the optimal length for active force production to longer lengths, which may exaggerate the force depression at low stimulation frequencies (Morgan \& Proske, 2004). 
The decrease in CAR was observed immediately after 200 DJs, while it did not change significantly after 50 DJs and 100 DJs and it shows that central activation is associated with stretch-shortening cycle exercise volume. Muscle fatigue may have inhibitory influence on central motor drive to keep the central output at a certain submaximal level presumably to avoid further accumulation of peripheral fatigue (Enoka \& Duchateau, 2008).

\section{CONCLUSION}

In conclusion, though indirect symptoms of exercise induced muscle damage manifested itself after 50, 100 and 200 DJs, however, it was considerable greater after 100 and 200 DJs. Besides the changes in central fatigue, height of DJs was only after 200 DJs.

Disclosure of conflicts of interest.The authors have no conflicts of interest.

\section{REFERENCES}

Allen, D. G., Lamb, G. D., \& Westerblad, H. (2008). Skeletal muscle fatigue: cellular mechanisms. Physiological Reviews, 88(1), 287-332. doi: 10.1152/physrev.00015.2007

BOSCO, C., Viitasalo, J. T., Komi, P. V., \& Luhtanen, P. (1982). Combined effect of elastic energy and myoelectrical potentiation during stretch-shortening cycle exercise. Acta Physiologica, 114(4), 557-565. doi: 10.1111/j.1748-1716.1982.tb07024.x

Byrne, C., Twist, C., \& Eston, R. (2004). Neuromuscular function after exercise-induced muscle damage. Sports Medicine, 34(1), 49-69.

Choi, S. J. (2014). Cellular mechanism of eccentricinduced muscle injury and its relationship with sarcomere heterogeneity. Journal of Exercise Rehabilitation, 10(4), 200. doi: 10.12965/jer.140139

Enoka, R. M., \& Duchateau, J. (2008). Muscle fatigue: What, why and how it influences muscle function. The Journal of Physiology, 586(1), 11-23. doi: 10.1113/ jphysiol.2007.139477

Fouré, A., Nosaka, K., Wegrzyk, J., Duhamel, G., Le Troter, A., Boudinet, H., ... \& Gondin, J. (2014). Time course of central and peripheral alterations after isometric neuromuscular electrical stimulation-induced muscle damage. Plos One, 9(9), e107298. doi: 10.1371/ journal.pone.0107298

Gorianovas, G., Skurvydas, A., Streckis, V., Brazaitis, M., Kamandulis, S., \& McHugh, M. P. (2013). Repeated bout effect was more expressed in young adult males than in elderly males and boys. BioMed Research International, 218970. doi: 10.1155/2013/218970

Kamandulis, S., Skurvydas, A., Masiulis, N., Mamkus, G., \& Westerblad, H. (2010). The decrease in electrically evoked force production is delayed by a previous bout of stretch-shortening cycle exercise. Acta Physiologica, 198(1), 91-98. doi: 10.1111/j.17481716.2009.02041.x

Miyama, M., \& Nosaka, K. (2007). Protection against muscle damage following fifty drop jumps conferred by ten drop jumps. Journal of Strength and Conditioning Research, 21(4), 1087-1092.

Morgan, D. L., \& Allen, D. G. (1999). Early events in stretch-induced muscle damage. Journal of Applied Physiology, 87(6), 2007-2015. DOI.ORG/10.1152/ JAPPL.1999.87.6.2007

Morgan, D. L., \& Proske, U. (2004). Popping sarcomere hypothesis explains stretch-induced muscle damage. Clinical and Experimental Pharmacology and Physiology, 31(8), 541-545. https://doi.org/10.1111/ j.1440-1681.2004.04029.x

Proske, U., \& Allen, T. J. (2005). Damage to skeletal muscle from eccentric exercise. Exercise and Sport Sciences Reviews, 33(2), 98-104.

Skurvydas, A., Brazaitis, M., Venckūnas, T., \& Kamandulis, S. (2011). Predictive value of strength loss as an indicator of muscle damage across multiple drop jumps. Applied Physiology, Nutrition, and Metabolism, 36(3), 353-360. doi: 10.1139/h11-023

Skurvydas, A., \& Zachovajevas, P. (1998). Is posttetanic potentiation, low frequency fatigue (LFF) and pre-contractile depression (PCD) coexistent in intermittent isometric exercises of maximal intensity? Acta Physiologica Scandinavica, 164, 127-133. doi: 10.1046/j.1365-201X.1998.00415.x

Verbickas, V., Kamandulis, S., Snieckus, A., Venckunas, T., Baranauskiene, N., Brazaitis, M., ... \& Skurvydas, A. (2018). Serum BDNF and IL-6 response to high-volume mechanically demanding exercise. Muscle \& Nerve, 57, E46-E51, doi: 10.1002/mus.25687 